\title{
Truck Selection with the Fuzzy-WSM Method in Transportation Systems of Open Pit Mines
}

\author{
Tahir MALLI, Pinar MIZRAK OZFIRAT*, Mustafa Emre YETKIN, Muharrem Kemal OZFIRAT
}

\begin{abstract}
Open pit mines gain width and become more complicated as they are deeper today, and it is inevitable to carry the produced material with a truck transportation system. Therefore, in large-scale businesses, truck selection has great importance for the transportation costs to be sustainable. This study investigates the main factors and corresponding criteria influential in selection of trucks, which are the most frequent used means of transportation in open pit mines. Analytic hierarchy process and fuzzy weighted sum model are employed to solve the selection problem. Six different truck types and 20 selection criteria are considered. As a result of technical analysis, most suitable trucks are found.
\end{abstract}

Keywords: Fuzzy Weighted-Sum Model (FWSM); mining truck; open pit mine; truck transportation

\section{INTRODUCTION}

Open pit mines get deeper and gain width as resources are consumed on the surface. In open pit mines, nearly one third of the unit cost comes from haulage operation. Since haulage makes up a substantial part of unit cost, these operations should be considered carefully and analysed in detail especially for technical and work safety factors. Improvement and upgrade work to be conducted in the transportation system, and reduction of transportation operation costs which are thought to be close to half of the operation costs by a few percentage points, will provide significant gains for the economy of the operation. Developments in the world's mining industry and increases in production are made possible by the usage of high capacity transportation vehicles. The aim to reduce unit costs necessitated the introduction of higher capacity, faster and technologically more advanced, well-equipped machinery and equipment.

Selection of machinery-equipment in mining is one of the most important parameters influential on the unit production cost. Parameters such as technical usability, economic goals, performance and workplace safety should be included in this assessment. Increased capacity of the machinery-equipment decreases its abilities in movement. On the other hand, with lower capacity, capability of movement increases, but the unit costs increase. Therefore, technical and economic parameters should be considered together for the pit where the operation will be run [1]. In the machinery-equipment selection stage, precise data must be used in compliance with mathematics and engineering application principles to find the economic solution $[2,3]$.

Selecting the most suitable equipment for transportation becomes an important factor that affects the cost [1]. Process of transportation consists of dynamic variables such as condition and grade of the roads, performance of the trucks etc. Condition of the road implies constantly changing parameters such as transportation distance, maximum allowed speed, stability and rolling resistance of the road. Each of these parameters influences transportation cycle-time for a truck (loaded and unloaded trips) and indirectly causes effects on the consumption of fuel, oil, hydraulics and furthermore on the economical life of equipment being used [4].
Transportation costs make up nearly half of operation costs [5]. Therefore decreasing transportation costs by a few points would save the mine considerable amount of money. Haulage can be made vertically, horizontally or in an inclined direction. In open operations, the transportation system is generally dependent on working conditions, reserve amounts, thickness and characteristics of top layer, annual production capacity, and layer-digging volume. Optimum machinery-equipment is selected for its suitability for the operating conditions and capacity. In many of the cases, two or more transportation modes can be employed together. When different haulage systems are considered, it can be seen that truck haulage has the smallest initial investment cost [6].

In addition, the most important factor in choosing truck transportation is that it has advantages of easy adaptation to rough land conditions in cover material and coal transportation when the mine is deeper, and its relatively lower fixed cost in the beginning, which provides economic advantages. The roughness of the land and the factor of slope of the coal make displacement among panels harder, but increase the applicability of truck transportation systems. Moreover, in cases of continuous transportation operations, any error or problem in the system may interrupt the continuity of the operation. The most important advantage is that the continuity of the transportation may be sustained even if one or more trucks are faulty in the line. Another benefit brought by this advantage is that trucks are able to work in different environments in the pit $[5,6]$. Considering all these advantages, it is inevitable to carry the produced material with a truck transportation system. Therefore, truck selection has great importance for the transportation costs to be sustainable.

However, while truck transportation systems are the most frequently preferred systems in open pit mining, their operating costs are higher in comparison to other systems of transportation. Therefore selecting the most suitable truck alternative becomes an important problem to decrease operation costs. In this study, the aim is to investigate the main factors and related criteria influential in selection of trucks. Then, alternative truck types are analysed based on the decision criteria and ranked according to overall performance.

Cost-effectiveness in mining requires working with high-capacity machinery. This makes the initial investment 
costs high. Many factors are effective in machine selection problems in mining. In such complicated problems, the selection can be made more reliably by using multi-criteria decision making (MCDM) tools.

In the study, truck selection problem in open pit mining is considered by MCDM. The tools used are analytic hierarchy process (AHP) and fuzzy weighted sum model (FWSM) respectively. AHP is employed to determine the influences of selection criteria on the decision and FWSM is employed to rank the decision alternatives (mine trucks). The proposed methodology integrates these two tools in an effective way. Also, by incorporating fuzzy logic into the truck selection problem, error, bias and subjectivity are decreased in the decision process.

\section{SELECTION PROBLEM}

Diversity of transportation in open pit mining may vary based on the developments in pit production aspects and increases in the depth of the site. Therefore, transportation selection problems, transportation vehicle capacity and cycle problems in mines are problems that are widely studied in the literature. Bascetin \& Kesimal [7], Naoum \& Haidar [8], Marzouk \& Moselhi [9], Wei et al. [10], Bitarafan \& Ataei [11], Samanta et al. [12] considered equipment selection at open pit mines, Yavuz [13] selected the production method of an underground mine, Ozkan et al. [14] evaluated resource classification, Ataei [15] handled facility location selection, Bottero \& Peila [16] compared two different excavation techniques, Yaria et al. [17] used TOPSIS method in addition to AHP and Kumar \& Kaur [18] considered fuzzy solid transportation problem for supplying coal in their studies.

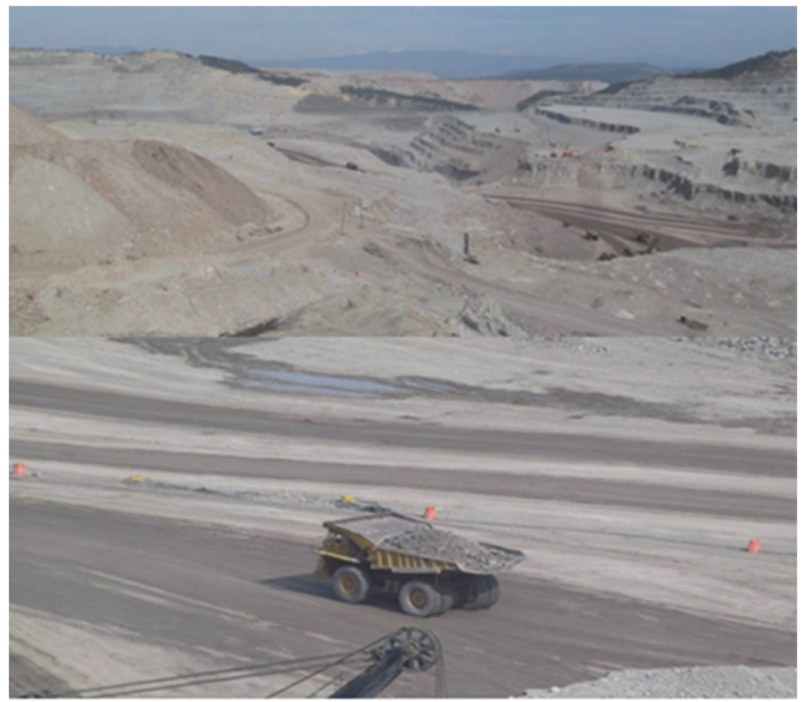

Figure 1 Open pit mine and truck transportation [20]

Truck selection problem is frequently encountered in open pit operations. However, truck selection may become a complicated problem based on annual stripping amounts and reserve amounts. While Kose et al. [4] mentioned the advantages of truck transportation in open pits, they emphasized that technical factors such as production type on the top layer, changes in loading areas, changes in transportation speed, and the physical and chemical characteristics of the loaded material must be investigated carefully. Also, it is stated in literature that inconvenient roads, inappropriate dumping and vibrations decrease the economic life of equipments $[5,6]$.

More recently, autonomous trucks are getting into use for both underground and surface mining. These trucks increase safety and decrease labour at the same time [19].

High-capacity trucks draw attention with their superiority over low-capacity trucks in terms of their hourly capacity and efficiency. The economy created by their advantages should also not be ignored. Thus, it is aimed to describe the specific characteristics and usage criteria of these trucks, and they need to be compared to other trucks in terms of technical and economic aspects. Truck transportation is showed in Fig. 1 [20].

\section{METHODOLOGY}

In the solution methodology, analytic hierarchy process (AHP) and fuzzy weighted sum model (F-WSM) is employed. In the first phase, AHP is used to determine the weight coefficients of decision criteria. Then these coefficients are turned into fuzzy triangular numbers and F-WSM is applied to determine the superior alternatives. The solution approach is explained in detail in the following.

\subsection{Determine Selection Criteria and Apply AHP to Compute Priorities}

The first step is to determine the decision criteria. Once these criteria are settled, AHP is employed to compute the priorities of each criterion. In addition to priority coefficients of decision criteria, inconsistency ratio is also computed. Let the inconsistency ratio be $R I$ inconsistency ratio is especially important for the proposed methodology because it will be used to transform crisp numbers to fuzzy numbers in step 2. Therefore, if value of $R I$ is greater than 0.1 , pairwise comparison matrices should be revised and priorities should be re-computed. If value of $R I$ is less than 0.1 , the procedure goes on with the next step.

\subsection{Develop Fuzzy Priorities}

The crisp priorities obtained by AHP in the first step are transformed into fuzzy triangular numbers in this step. Let $p_{i}$ be the priority coefficient computed for criterion $i$. Then, the priority matrix obtained by AHP for the $n$ decision criteria would be as in Eq. (1).

$$
P=\left[p_{1}, p_{2}, p_{3}, \ldots, p_{n}\right]
$$

In order to transform crisp priorities into fuzzy triangular numbers, a lower bound and an upper bound should be computed. Let the fuzzy triangular number to represent crisp priority $p_{i}$ be:

$$
\left[l p_{i}, p_{i}, u p_{i}\right]
$$

where:

$l p_{i}$ : lower bound for priority $p_{i}$, $u p_{i}$ : upper bound for priority $p_{i}$. 
Then $l p_{i}$ and $u p_{i}$ are computed as in Eqs. (3) and (4) respectively.

$$
\begin{aligned}
& l p_{i}=(1-R I) \times p_{i} \\
& u p_{i}=(1+R I) \times p_{i}
\end{aligned}
$$

These bounds are found based on the idea that since there exists $R I$ amount of inconsistency in AHP calculations, the consistent values of the corresponding priorities can be found by adding and subtracting this $R I$ amount from the value of the priority.

\subsection{Develop Fuzzy Priorities}

Once the decision criteria and fuzzy triangular priorities are settled, alternative decision options should be identified. Let there be $k$ alternative options. Fuzzy performance matrices for all $k$ alternatives according to all decision criteria should be developed (Eq. 5). In other words, the performance of each alternative should be represented by a fuzzy triangular number. In order to do so, the worst case, most likely and the best case performance scores should be determined for all $k$ alternatives.

$$
\text { Performance }=\left[\begin{array}{ccc}
w_{1} & m_{1} & b_{1} \\
\ldots & \ldots & \ldots \\
w_{k} & m_{k} & b_{k}
\end{array}\right]
$$

where:

$w_{i}$ : worst case performance score for alternative $i$, $m_{i}$ : most likely performance score for alternative $i$, $b_{i}$ : best case performance score for alternative $i$.

\subsection{Compute Overall Performance Using Fuzzy-Weighted Sum Model}

In this step, fuzzy weighted sum model is employed to find the overall fuzzy performances of each alternative (Eq. (6)).

$$
P_{i}=\left[\sum w_{i} \cdot p_{i}, \quad \sum m_{i} \cdot p_{i}, \quad \sum b_{i} \cdot u p_{i}\right] \forall i=1, \ldots, k
$$

Eq. (6) outputs fuzzy triangular numbers representing the performance of alternative trucks. The corresponding membership functions for the fuzzy triangular numbers are given as in Eq. (7).

$$
\mu_{i}(x)=\left\{\begin{array}{c}
0 \text { if } x \leq \sum w_{i} \cdot l p_{i} \text { or } \sum b_{i} \cdot u p_{i}<x \\
\frac{x-\sum w_{i} \cdot l p_{i}}{\sum m_{i} \cdot p_{i}-\sum w_{i} \cdot l p_{i}} \text { if } \sum w_{i} \cdot l p_{i}<x \leq \sum m_{i} \cdot p_{i} \\
\frac{\sum b_{i} \cdot u p_{i}-x}{\sum b_{i} \cdot u p_{i}-\sum m_{i} \cdot p_{i}} \text { if } \sum m_{i} \cdot p_{i}<x \leq \sum b_{i} \cdot u p_{i}
\end{array}\right\}
$$

\subsection{Comparison and Ranking of Fuzzy Performances}

When two fuzzy triangular numbers (Overall Performance $i$ and Overall Performance $j$ ) are with membership functions $\mu i(x)$ and $\mu j(y)$ compared, Overall Performance $i$ dominates Overall Performance $j$ if the following conditions (Eq. (8)) are satisfied [21]:

$d_{i j}=1$ and $d_{j i}<$ Threshold

where $d_{i j}$ is computed as in Eq. (9) and Threshold can be determined to be $0.7,0.8$ or 0.9 by the decision makers of the system [21].

$d_{i j}=\max _{x \geq y}\left\{\min \left(\mu_{i}(x), \mu_{j}(y)\right\}\right.$

In this study, Threshold is determined to be 0.9 and the methodology is applied to rank the overall performances of mine trucks.

\section{APPLICATION OF THE MODEL METHODOLOGY}

The model implementation explained in the previous section of the study is applied to GLI's open pit. Tunçbilek coalfield is located $50 \mathrm{~km}$ far from Kutahya province and $13 \mathrm{~km}$ far from the district of Tavsanli. Significant portion of the lignite reserves in Turkey is located in Tuncbilek (252.5 million tons). About 7\% of the country's lignite production is provided by this area. The produced coal is fed from here to the thermal power plant with the installed power of $365 \mathrm{MW}$ [20]. Tab. 1 shows the important parameters of production for the operation.

Table 1 The Operation's Technical Values [20]
\begin{tabular}{|l|c|}
\hline \multicolumn{1}{|c|}{ Production parameters } & Values \\
\hline Coal calorific value & $2560 \mathrm{kcal} / \mathrm{kg}$ \\
\hline Annual coal production (from open pit) & $4.5 \mathrm{million}$ ton \\
\hline Annual stripping (from TKI) & $10 \mathrm{million} \mathrm{\textrm {m } ^ { 3 }}$ \\
\hline Stripping ratio & $13 \mathrm{~m}^{3} / \mathrm{t}$ \\
\hline Total reserve amount & $252.5 \mathrm{million}$ tons \\
\hline Installed Thermic plant power & $365 \mathrm{MW}$ \\
\hline
\end{tabular}

Garp Lignite Company provides approximately $87 \%$ of the programmed 4.5 million ton/year raw lignite coal production from the open pit. In preparation of panels for coal production in the open operation, dragline and excavator-truck layer digging is used. The average layer digging ratio is 13 , and approximately $10000000 \mathrm{~m}^{3}$ of top layer digging is made to achieve annual planned coal production [20]. Striping trucks are considered in this study. The detailed case study is given in the following.

\subsection{Determine Selection Criteria and Apply AHP to Compute Priorities}

The purpose of the model study is to determine the truck capacities to be selected during the transportation of 10 million $\mathrm{m}^{3}$ of material through a year. The main purpose of the model, main criteria and Sub-criteria are given in Fig. 2 and Tab. 2.

As seen in Tab. 2, main criteria groups are Economy (C1), Technical constraints (C2), work safety (C3) and Truck properties (C4) respectively. Each of these groups are considered in detail in the following.

Economy (C1): Economy criteria are fuel consumption (C11), working time (C12), initial investment cost (C13), Depreciation (C14), Material transportation unit cost (C15) 
according to the literature studies and authors of the study [22-24]. Annual average working time of mine trucks are important. Accordingly, the ratios of electrical failures and mechanical failures in the total active and stationary times of the truck are important. A low value of these ratios in total hours indicates a high efficiency for these trucks. In addition, depreciation and unit cost also are important factors. Especially, initial investment cost and operating cost quite affect truck selection problem [25]. For example, more tonnage trucks investment is more expensive but operating cost is less.

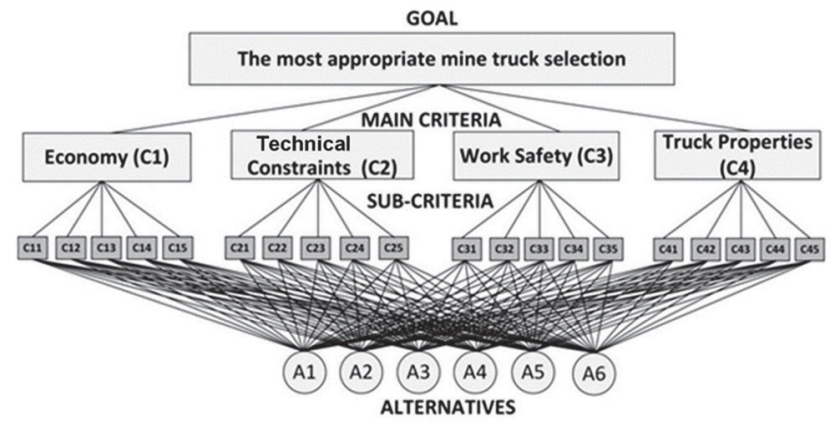

Figure 2 Decision hierarchy for the mine truck selection problem

Table 2 Main Criteria and Sub-Criteria for the Truck Selection Problem

\begin{tabular}{|l|l|}
\hline \multicolumn{1}{|c|}{ C1: Economy } & \multicolumn{1}{|c|}{ C2: Technical constraints } \\
\hline C11: Fuel consumption & C21: Efficiency \\
C12: Working time & C22: Compatibility capacity of \\
C13: Initial investment cost & truck and loader \\
C14: Depreciation & C23: Transport capacity \\
C15: Material transportation unit & C24: Slope of the transportation \\
cost & route \\
& C25: Production system \\
\hline \multicolumn{1}{|c|}{ C3: Work safety } & \multicolumn{1}{|c|}{ C4: Truck properties } \\
\hline C31: Technology and safety & C41: Truck capacity \\
systems & C42: Engine power \\
(Navigation, truck dispatching & C43: Engine type \\
system etc.) & C44: Gearbox \\
C32: Vibration and impact & C45: Equipment \\
strength of the truck vessel & \\
C33: Gas emissions & \\
C34: Cabin comfort and & \\
ergonomics & \\
C35: Noise & \\
\hline
\end{tabular}

Technical constraints (C2): Technical constraints can be grouped as efficiency (C21), compatibility capacity of truck and loader (C22), transport capacity (C23), slope of the transportation route $(\mathrm{C} 24)$ and production system (C25). Especially Ta et al. [26] and Ankara et al. [27] emphasized that working times should be more than failure times of trucks for efficiency. Compatibility capacity of truck-loader and transport capacity are primarily important in the determination of the amount of material to be transported hourly [28]. On the other hand, pit roads must be designed with $8-12 \%$ of slope for the best efficiency of trucks. Finally, production system also affects truck selection. Two sided maneuvering system is more preferred in operations as it reduces cycle time [4].

Work safety (C3): Work safety criteria are Technology and safety systems (C31), vibration and impact strength of the truck vessel (C32), gas emissions (C33), cabin comfort and ergonomics (C34) and noise (C35). Ozfirat et al. [29] and Mutlu [30] has shown that about $30 \%$ of accidents in ELI open pits were caused by mining machinery and equipment. Today, navigation, truck dispatching system has been developed. Malli et al. [31] emphasized navigation, GPS-based, truck allocation-monitoring system technologies. Big mining machinery firms have developed monitoring, mining machinery allocation, defining potential hazards and alert to operators around their machines which assure safer working conditions. In addition, these systems serve mines as a comprehensive overview of all operations with real time machine tracking and productivity management. Moreover, working with comfortable, noise-reducing cabin systems with low vibration, environment-friendly engines with catalytic converter systems and Euro 5-compatible emissions, would reduce the amount of workplace accidents and increase the standards of workplace safety.

Truck properties (C4): Truck properties are also important for truck selection problem. Truck properties are determined as truck capacity (C41), engine power (C42), engine type (C43), gearbox (C44). Truck capacity is the most important for truck selection problem. For example, investment in large-capacity trucks is inevitable in deep open pit mines with an annual stripping amount of more than 5-10 million tons. As Kose et al. [4] emphasize, as the mine gets deeper, electric power type becomes more economical and more environment-friendly instead of diesel power. In addition, since mine conditions are difficult, truck manufacturers must produce machine attachments and equipment resistant to mine conditions.

Table 3 Priorities for decision criteria found by AHP

\begin{tabular}{|c|c|c|c|}
\hline \multicolumn{2}{|c|}{ C1: Economy } & \multicolumn{2}{c|}{ C2: Technical constraints } \\
\hline C11 & 0.094 & C21 & 0.039 \\
\hline C12 & 0.025 & C22 & 0.056 \\
\hline C13 & 0.054 & C23 & 0.080 \\
\hline C14 & 0.054 & C24 & 0.012 \\
\hline C15 & 0.182 & C25 & 0.015 \\
\hline Sum & 0.409 & Sum & 0.202 \\
\hline C3: Work safety & C4: Truck properties \\
\hline C31 & 0.139 & C41 & 0.035 \\
\hline C32 & 0.064 & C42 & 0.025 \\
\hline C33 & 0.021 & C43 & 0.014 \\
\hline C34 & 0.040 & C44 & 0.008 \\
\hline C35 & 0.028 & C45 & 0.015 \\
\hline Sum & 0.292 & Sum & 0.097 \\
\hline \multicolumn{4}{|c|}{ Overall Inconsistency Ratio $=0.097$} \\
\hline
\end{tabular}

After determination of the decision criteria, AHP is applied to find priority coefficients of all criteria. The priorities can be seen in Tab. 3 above. Economy (C1) turned out to be the most effective criteria group in truck selection and work safety (C3) takes the second place. In addition, it is found that transportation unit cost $(\mathrm{C} 15$ : 0.182), technology and safety systems (C31: 0.139), fuel consumption (C11: 0.094) and work capacity (C23: 0.08) are primarily important. Also, the overall inconsistency ratio is found to be 0.097 . This is an acceptable level since it is less than 0.1 Threshold.

\subsection{Develop Fuzzy Priorities}

At this step, crisp priorities given in Tab. 3 are transformed into fuzzy priorities using the overall inconsistency ratio and applying Eqs. (3) and (4). Fuzzy priorities belonging to each decision criterion can be seen in Tab. 4. 
Table 4 Fuzzy priorities for decision criteria

\begin{tabular}{|c|c|c|c|}
\multicolumn{5}{|c}{ Table 4 Fuzzy priorities for decision criteria } \\
\hline & Lower & Middle & Upper \\
\hline C11 & 0.085 & 0.094 & 0.103 \\
\hline C12 13 & 0.022 & 0.025 & 0.027 \\
\hline C14 & 0.048 & 0.054 & 0.059 \\
\hline C15 & 0.049 & 0.054 & 0.059 \\
\hline C21 & 0.164 & 0.182 & 0.200 \\
\hline C22 & 0.035 & 0.039 & 0.043 \\
\hline C23 & 0.051 & 0.056 & 0.062 \\
\hline C24 & 0.073 & 0.080 & 0.088 \\
\hline C25 & 0.013 & 0.012 & 0.014 \\
\hline C31 & 0.125 & 0.015 & 0.016 \\
\hline C32 & 0.058 & 0.139 & 0.152 \\
\hline C33 & 0.019 & 0.064 & 0.071 \\
\hline C34 & 0.036 & 0.021 & 0.023 \\
\hline C35 & 0.025 & 0.040 & 0.044 \\
\hline C41 & 0.032 & 0.035 & 0.031 \\
\hline C42 & 0.022 & 0.025 & 0.039 \\
\hline C43 & 0.012 & 0.014 & 0.027 \\
\hline C44 & 0.008 & 0.008 & 0.015 \\
\hline C45 & 0.014 & 0.015 & 0.016 \\
\hline
\end{tabular}

\subsection{Identify Alternative Options and Develop Fuzzy Performance Matrices}

Nowadays, electric drive mine trucks reach up to 400 tons [32]. In the modelling studies, mine stripping trucks with six different capacities were considered. According to Burt \& Caccetta [23], Burt et al. [33] and Topal \& Ramazan [34], 5 to 25 different types of trucks may be used. However, considering the widespread usage in the most general sense and the conditions of the study site, alternative options given in Tab. 5 are considered [35]. As diesel trucks are used in the area, all types are considered to be diesel trucks.

Table 5 Truck options [35]

\begin{tabular}{|c|c|c|}
\hline Alternatives & Capacity (ton) & Class \\
\hline A1: Mine Truck 1 & $\leq 35$ tons & Light \\
\hline A2: Mine Truck 2 & $35<$ capacity $<55$ tons & Light Medium \\
\hline A3: Mine Truck 3 & $55<$ capacity $<85$ tons & Medium \\
\hline A4: Mine Truck 4 & $85<$ capacity $<170$ tons & Medium \\
\hline A5: Mine Truck 5 & $170<$ capacity $<270$ tons & Medium-Heavy \\
\hline A6: Mine Truck 6 & $270<$ capacity tons & Heavy \\
\hline
\end{tabular}

After the types of trucks are determined, they are analysed based on all criteria according to fuzzy logic. Tab. 6 shows the fuzzy triangular numbers representing the performances of each alternative truck. In the analysis, types of trucks are given a score of 0 to 100 based on the criterion performance. For example, line C13 in Tab. 4 gives the performance scores based on the initial investment criterion. As initial investment costs increase with the capacity of the trucks, lowest performance belongs to A6 (which has the highest capacity). In addition, the fuzzy performance for this truck is determined to be $(55$, $65,75)$ which shows the worst case, most likely and best case performance scores respectively.

Table 6 Fuzzy performance scores of alternative mine trucks

\begin{tabular}{|c|c|c|c|c|c|c|}
\hline Criteria & A1 & A2 & $\mathrm{A} 3$ & $\mathrm{~A} 4$ & A5 & A6 \\
\hline C11 & $(60,75,80)$ & $(55,65,75)$ & $(60,70,75)$ & $(65,75,80)$ & $(75,80,90)$ & $(85,95,100)$ \\
\hline $\mathrm{C} 12$ & $(75,80,85)$ & $(70,75,80)$ & $(70,80,85)$ & $(65,75,80)$ & $(70,75,80)$ & $(65,70,75)$ \\
\hline $\mathrm{C} 13$ & $(80,90,100)$ & $(75,80,95)$ & $(70,80,90)$ & $(65,75,85)$ & $(60,70,80)$ & $(55,65,75)$ \\
\hline $\mathrm{C} 14$ & $(65,70,75)$ & $(65,75,80)$ & $(65,80,85)$ & $(70,85,90)$ & $(85,90,95)$ & $(90,95,100)$ \\
\hline $\mathrm{C} 15$ & $(60,65,70)$ & $(50,55,60)$ & $(60,65,70)$ & $(70,75,80)$ & $(75,80,90)$ & $(90,95,100)$ \\
\hline $\mathrm{C} 21$ & $(65,70,75)$ & $(65,75,80)$ & $(75,80,85)$ & $(70,85,90)$ & $(85,90,95)$ & $(90,95,100)$ \\
\hline $\mathrm{C} 22$ & $(85,90,95)$ & $(75,80,85)$ & $(70,75,80)$ & $(65,75,80)$ & $(65,70,75)$ & $(60,65,70)$ \\
\hline $\mathrm{C} 23$ & $(60,65,70)$ & $(65,70,75)$ & $(70,75,80)$ & $(70,75,85)$ & $(75,80,90)$ & $(85,90,95)$ \\
\hline $\mathrm{C} 24$ & $(70,75,80)$ & $(65,75,80)$ & $(65,70,75)$ & $(65,70,75)$ & $(60,65,70)$ & $(60,65,70)$ \\
\hline $\mathrm{C} 25$ & $(85,90,95)$ & $(80,85,95)$ & $(80,85,95)$ & $(80,85,90)$ & $(75,80,90)$ & $(75,80,85)$ \\
\hline C31 & $(65,70,75)$ & $(65,70,80)$ & $(75,80,85)$ & $(80,85,90)$ & $(85,90,95)$ & $(90,95,100)$ \\
\hline $\mathrm{C} 32$ & $(65,70,75)$ & $(65,70,75)$ & $(70,75,80)$ & $(70,75,80)$ & $(70,75,85)$ & $(80,85,90)$ \\
\hline $\mathrm{C} 33$ & $(90,95,100)$ & $(85,90,95)$ & $(80,85,90)$ & $(75,80,85)$ & $(65,70,80)$ & $(65,70,75)$ \\
\hline $\mathrm{C} 34$ & $(65,70,75)$ & $(65,70,75)$ & $(70,75,80)$ & $(70,75,80)$ & $(70,75,85)$ & $(80,85,90)$ \\
\hline $\mathrm{C} 35$ & $(75,80,85)$ & $(75,80,85)$ & $(65,75,80)$ & $(65,75,80)$ & $(65,70,75)$ & $(65,70,75)$ \\
\hline $\mathrm{C} 41$ & $(70,75,80)$ & $(75,80,85)$ & $(80,85,90)$ & $(80,85,90)$ & $(85,90,95)$ & $(90,95,100)$ \\
\hline $\mathrm{C} 42$ & $(70,75,80)$ & $(75,80,85)$ & $(80,85,90)$ & $(80,85,90)$ & $(85,90,95)$ & $(90,95,100)$ \\
\hline $\mathrm{C} 43$ & $(70,75,80)$ & $(75,80,85)$ & $(80,85,90)$ & $(80,85,90)$ & $(80,90,95)$ & $(85,95,100)$ \\
\hline $\mathrm{C} 44$ & $(70,75,80)$ & $(70,80,85)$ & $(80,85,90)$ & $(80,85,90)$ & $(80,85,95)$ & $(80,90,100)$ \\
\hline $\mathrm{C} 45$ & $(70,75,80)$ & $(75,80,85)$ & $(80,85,90)$ & $(80,85,90)$ & $(85,90,95)$ & $(90,95,100)$ \\
\hline
\end{tabular}

\subsection{Compute Overall Performance Using Fuzzy-Weighted Sum Model}

Overall performance for each of the six alternative mine trucks are computed using FWSM. Results can be seen in Tab. 7. In addition the membership functions belonging to each fuzzy performance are presented in Fig. 3.

Table 7 Overall fuzzy performance scores of alternative mine trucks

\begin{tabular}{|c|c|}
\hline Mine Truck & Overall Performance in Fuzzy Triangular Numbers \\
\hline A1 & $(60.54 ; 73.25 ; 86.14)$ \\
\hline A2 & $(58.16 ; 70.44 ; 84.70)$ \\
\hline A3 & $(62.30 ; 75.53 ; 88.71)$ \\
\hline A4 & $(64.35 ; 78.48 ; 92.31)$ \\
\hline A5 & $(68.16 ; 80.82 ; 97.21)$ \\
\hline A6 & $(73.98 ; 87.77 ; 102.11)$ \\
\hline
\end{tabular}

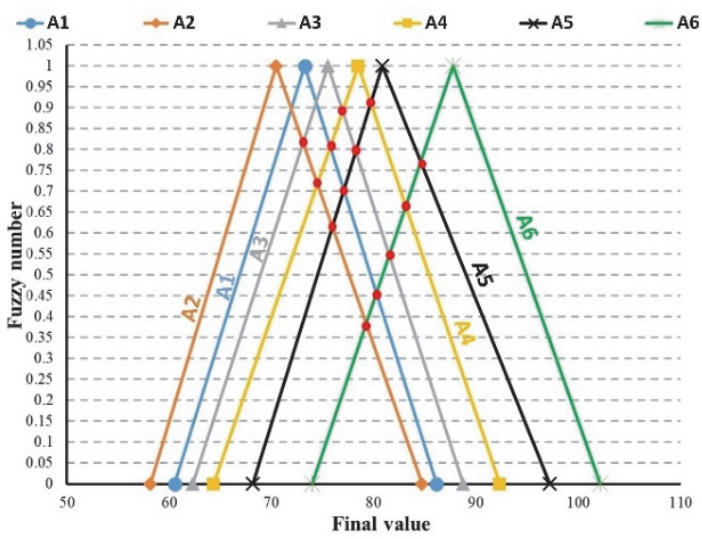

Figure 3 Membership functions fuzzy performances of mine trucks 


\subsection{Comparison and Ranking of Fuzzy Performances}

When ranking fuzzy performances of mine trucks, Threshold level is determined to be $0.9 . d_{i j}$ values are computed according to Eq.(9) and presented in Tab. 8.

Table $8 d_{i j}$ values to rank overall fuzzy performances of mine trucks

\begin{tabular}{|c|c|c|c|c|c|c|}
\hline$j$ & 1 & 2 & 3 & 4 & 5 & 6 \\
\hline 1 & - & 1 & 0.91 & 0.81 & 0.7 & 0.46 \\
\hline 2 & 0.895 & - & 0.82 & 0.72 & 0.62 & 0.38 \\
\hline 3 & 1 & 1 & - & 0.89 & 0.8 & 0.55 \\
\hline 4 & 1 & 1 & 1 & - & 0.91 & 0.67 \\
\hline 5 & 1 & 1 & 1 & 1 & - & 0.77 \\
\hline 6 & 1 & 1 & 1 & 1 & 1 & - \\
\hline
\end{tabular}

Considering the conditions given in Eq. (8), it can be seen from Tab. 8 that,

- Mine truck 6 dominates all other alternatives $\left(d_{6 j}=1\right.$ and $d_{i 6}<0.9$ for all $i \neq 6$ and $j \neq 6$ ).

- Mine truck 5 dominates mine trucks 3, 1 and 2 . However, we are indifferent between mine truck 5 and 4 (Since $\left.d_{45}=0.91>0.9\right)$.

- $\quad$ Mine truck 4 dominates mine trucks 3, 1 and 2.

- Mine truck 3 dominates mine trucks 2. However, we are indifferent between mine truck 3 and 1 (Since $d_{13}$ $=0.91>0.9$ ).

- $\quad$ Mine truck 1 dominates mine truck 2 .

\section{DISCUSSIONS AND RESULTS}

Developments in the world's mining industry and increases in production are made possible by the usage of high-capacity transportation vehicles. Technologically more advanced machinery-equipment has more advantages in minimization of unit cost, and maximization of work safety standards.

The effects of the main factors and the Sub-criteria in selection of trucks are investigated with the method of AHP and FWSM. It is found that among the main criteria groups, economy (C1: 0.409) and work safety (C3: 0.292) criteria have the highest influences on the decision. In addition, among the Sub-criteria, it is observed that especially the transportation unit cost is effective. Bozorgebrahimi et al. [22], Kose et al. [4], Burt \& Caccetta [23], Kose \& Kahraman [25] emphasized importance of economic analysis on truck selection problem. Similar to these studies, the most important selection criterion is determined to be economic analysis. However, different from these studies in the literature, this study considers truck selection problem using a fuzzy model. Also, work safety is found to be the second influencing criterion. This is an expected result since work safety rules and regulations are getting more important in today's manufacturing environment. Therefore, working with safer technologies and safer work regulations in mining have made the work safety criterion important in truck selection problem. Truck manufacturers are now trying to eliminate all the hazards that will occur in the open pit with GPS navigation, truck monitoring, truck dispatch, machine maintenance and efficiency monitoring systems.

As a result of the FWSM analysis, it is found that Mine Truck 6 (capacity $>270$ tons: heavy) is determined to be the most suitable for the area under study. Mine Truck 5 $(170<$ capacity $<270$ tons: medium-heavy) and Mine Truck 4 ( $85<$ capacity $<170$ tons: medium) are found as equivalent to each other in the selection. Mine Truck 1 and Mine Truck 3 may be considered equivalent, and more preferable compared to Mine Truck 2. The results show that large capacity truck investments are preferred, especially in deep and large capacity mines.

\section{CONCLUSION}

Selection problems are the most difficult ones especially in mining studies, because machinery investments are highly costly investments. Thus, in cases where the wrong machinery or machinery with the wrong capacity is used, operations are not cost-effective and they may even come to a point of stopping. This creates serious problems for mines. Therefore, decision problems in mining must be analysed in detail by multi-criteria decision making techniques. In the study, truck selection problem in an open pit mine is handled and a solution methodology integrating AHP and FWSM is proposed. With the incorporation of fuzzy logic, the model leads to solutions prone to less error and bias. The methodology is also applied to real life case study. In the solutions, ranking of alternative truck types according to their overall performances are computed and presented.

\section{REFERENCES}

[1] Morgan, B. (2000). Cost Effective Equipment Applications Zones. Mine Planning and Equipment Selection, 323-328.

[2] Mizrak Ozfirat, P. (2014). A New Risk Analysis Methodology Integrating Fuzzy Prioritization Method and Failure Modes And Effects Analysis. Journal of the Faculty of Engineering and Architecture of Gazi University, 29(4), 755-768. https://doi.org/10.17341/gummfd.04423

[3] Mizrak Ozfirat, P., Ozfirat, M. K., Malli, T., \& Kahraman, B. (2015). Integration of fuzzy analytic hierarchy process and multi-objective fuzzy goal programming for selection problems: An application on road header selection. Journal of Intelligent \& Fuzzy Systems, 29, 53-62. https://doi.org/10.3233/IFS-151569

[4] Kose, H., Yalcin, E., Simsir, F., Konak, G., Onargan, T., \& Kizil, M. S. (2009). Open Pit Mining. DEU Faculty of Engineering, Izmir, Turkey (in Turkish).

[5] Alarie, S. \& Gamache, M. (2002). Overview of solution strategies used in truck dispatching systems for open pit mines. International Journal of Surface Mining, Reclamation and Environment, 16(1), 59-76. https://doi.org/10.1076/ijsm.16.1.59.3408

[6] Mizrak Ozfirat, P., Ozfirat, M. K., \& Malli, T. (2017). Selection of Coal Transportation Mode From the Open Pit Mine to the Thermic Power Plant Using Fuzzy Analytic Hierarchy Process (FAHP). Transport, 33(2), 502-509. https://doi.org/10.3846/16484142.2017.1295278

[7] Bascetin, A. \& Kesimal, A. (1999). The study of a fuzzy set theory for the selection of an optimum coal transportation system from pit to the power plant. International Journal of Surface Mining, Reclamation and Environment, 13(3), 97101. https://doi.org/10.1080/09208119908944224

[8] Naoum, S. \& Haidar, A. (2000). A hybrid knowledge base system and genetic algorithms for equipment selection. Engineering, Construction and Architectural Management, 7(1), 3-14. https://doi.org/10.1108/eb021128

[9] Marzouk, M. \& Moselhi, O. (2002). Simulation optimization for earthmoving operations using genetic algorithms. Construction Management and Economics, 20(6), 535-543. https://doi.org/10.1080/01446190210156064 
[10] Wei, Y., Fan, Y., \& Xu, W. (2003). An integrated methodology for decision making of mining method selection. International Journal of Manufacturing Technology and Management, 5(1/2), 10-19. https://doi.org/10.1504//JMTM.2003.002525

[11] Bitarafan, M. \& Ataei, M. (2004). Mining method selection by multiple criteria decision making tools. The Journal of the South African Institute of Mining and Metallurgy, 104(9) 493-498.

[12] Samanta, B., Sarkar, B., \& Murherjee, S. K. (2002). Selection of opencast mining equipment by a multi-criteria decision-making process. Mining Technology, 111, 136-142. https://doi.org/10.1179/mnt.2002.111.2.136

[13] Yavuz, M. (2015). The application of the analytic hierarchy process (AHP) and Yager's method in underground mining method selection problem. International Journal of Mining, Reclamation and Environment, 29(6), 453-475. https://doi.org/10.1080/17480930.2014.895218

[14] Ozkan, E., Iphar, M., \& Konuk, A. (2019). Fuzzy logic approach in resource classification. International Journal of Mining, Reclamation and Environment, 33(3), 183-205. https://doi.org/10.1080/17480930.2017.1381219

[15] Ataei, M. (2005). Multi-criteria selection for aluminacement plant location in East-Azerbaijan province of Iran. Journal of South African Institute of Mining and Metallurgy, 105, 507-514.

[16] Bottero, M., Peila, D. (2005). The use of the Analytic Hierarchy Process for the comparison between microtunnelling and trench excavation, Tunnelling and Underground Space Technology 20, 501-513. https://doi.org/10.1016/j.tust.2005.03.004

[17] Yaria, M., Monjezi M., \& Bagherpour, R. (2013). Selecting the most suitable blasting pattern using AHP-TOPSIS method: Sungun copper mine. Journal of Mining Science, 49, 967-975. https://doi.org/10.1134/S1062739149060178

[18] Kumar, A. \& Kaur, A. (2014). Optimal way of selecting cities and conveyances for supplying coal in uncertain environment, Sadhana, 39(1), 165-187. https://doi.org/10.1007/s12046-013-0207-4

[19] Zamorano, S. (2011). Surface Ore Movement, Storage, and Recovery Systems. SME: Society Mining Engineering Handbook, Darling, P., (Ed.), Third Edition, 977-987.

[20] TKI, (2016). Annual Operations Report of 2015, Turkish Coal Administrations, May, 2016, Ankara (in Turkish).

[21] Triantaphyllou, E. (2000). Multi-Criteria Decision Making Methods: A Comparative Study. Book edited by Parlos, P. M. https://doi.org/10.1007/978-1-4757-3157-6

[22] Bozorgebrahimi, A., Hall, R., \& Morin, M. (2005). Equipment size effects on open pit mining performance. International Journal of Surface Mining, Reclamation and Environment, 19(1), 41-56. https://doi.org/10.1080/13895260412331326821

[23] Burt, C. N. \& Caccetta, L. (2014). Equipment Selection for Surface Mining: A Review. Interfaces, 44(2), 143-162. https://doi.org/10.1287/inte.2013.0732

[24] Klanfar, M., Korman, T., \& Kujundzic, T. (2016). Fuel consumption and engine load factors of equipment in quarrying of crushed stone. Technical gazette, 23(1), 163169. https://doi.org/10.17559/TV-20141027115647

[25] Kose, H. \& Kahraman, B. (2014). Mining Operating Economics. 4th edition, DEU Faculty of Engineering Publishing, No:223, Izmir, Turkey (in Turkish).

[26] Ta, C. H., Ingolfsson, A., \& Doucette, J. (2013). A linear model for surface mining haul truck allocation incorporating shovel idle probabilities. European Journal of Operational Research, 231, 770-778. https://doi.org/10.1016/j.ejor.2013.06.016

[27] Ankara, H., Yerel, S., \& Konuk, A. (2007). Determining equalities of trucks in the Open-Pit Mine using two Example
Kolmogorov-Smirnov (K-S) test. Science and Engineering Journal of Firat University, 19(1), 105-108 (in Turkish).

[28] Blackwell, G. H. (1999). Estimation of large open pit haulage truck requirements. CIM Bulletin, 92(1028), 143148.

[29] Ozfirat, M. K., Sengun, B., \& Yetkin, M. E. (2011). Risk Evaluation and Management in Mines. Proceedings Book of the Work safety and Healty Symposium in Mines, 24-25 ${ }^{\text {th }}$ November, Zonguldak, Turkey (in Turkish).

[30] Mutlu, M. (2013). Evaluation of Occupational Accidents in Opencast Mining Enterprises by Using Logistic Regression Analysis Method. Master of Science Thesis, Osmangazi University.

[31] Malli, T., Konak, G., Kose, H., Karakus, D., \& Gonen, A. (2011). The Dynamic Truck Dispatching System in Open Pit Mining. 3rd Mining Machinery Symposium, May 05-06, Izmir, Turkey, 283-292.

[32] Wisely, T., Seiwell, J., Surrat, D. (2017). Komatsu technical report. Electrical Dump Truck 980E-4, 63(170).

[33] Burt, C., Caccetta, L., Welgama, P., \& Fouch'e, L. (2011). Equipment selection with heterogeneous fleets for multiple period schedules. Journal of the Operational Research Society, 62, 1498-1509. https://doi.org/10.1057/jors.2010.107

[34] Topal, E. \& Ramazan, S. (2010). A new MIP model for mine equipment scheduling by minimizing maintenance cost. European Journal of Operational Research, 207(2), 10651071. https://doi.org/10.1016/j.ejor.2010.05.037

[35] Caterpillar, (1998). Caterpillar Performance Handbook. 29 $9^{\text {th }}$ ed. Caterpillar Inc., Peoria, Illinois, USA.

\section{Contact information:}

Tahir MALLI, Dr.

Dokuz Eylul University, Mining Engineering Dept.,

Tinaztepe Kampusu 35390 Buca-Izmir/TURKEY

E-mail: tahir.malli@deu.edu.tr

PInar MIZRAK ÖZFIRAT, Associate Professor, Dr.

(Corresponding author)

Manisa Celal Bayar University, Industrial Engineering Dept.,

Sehit Prof. Dr. Ilhan Varank Kampusu Yunusemre, Manisa/TURKEY

E-mail: pinar.ozfirat@cbu.edu.tr

\section{Mustafa Emre YETKIN, Dr.}

Dokuz Eylul University, Mining Engineering Dept.,

Tinaztepe Kampusu 35390 Buca-Izmir/TURKEY

E-mail: mustafa.yetkin@deu.edu.tr

Muharrem Kemal ÖZFIRAT, Associate Professor, Dr.

Dokuz Eylul University, Mining Engineering Dept.

Tinaztepe Kampusu 35390 Buca-Izmir/TURKEY

E-mail: kemal.ozfirat@deu.edu.tr 